\title{
Scleral Thinning after Transscleral Biopsy for Uveal Melanoma Using Lamellar Scleral Flap
}

\author{
Diane T. Siegel $^{a} \quad$ Eszter Szalai $^{a} \quad$ Jill R. Wells ${ }^{a}$ Hans E. Grossniklaus a, b

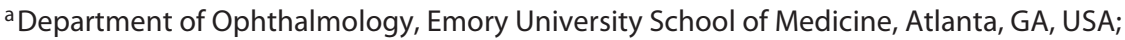 \\ ${ }^{b}$ Department of Pathology, Emory University School of Medicine, Atlanta, GA, USA
}

\section{Established Facts}

- The transscleral biopsy technique for uveal melanoma without the use of a lamellar scleral flap is associated with a low risk of complications.

- Distinguishing scleral necrosis from extraocular tumor extension can be difficult and is made on the basis of clinical findings.

\section{Novel Insights}

- The use of a partial-thickness lamellar scleral flap may increase risk of development of scleral thinning and possible extraocular tumor extension.

- A scleral flap for biopsy of uveal melanoma should be used with caution.

\section{Keywords}

Uveal melanoma $\cdot$ Transscleral biopsy · Lamellar scleral flap · Scleral necrosis · Scleral thinning

\begin{abstract}
Purpose: The purpose of the study is to describe the clinical history and histopathologic findings of three cases of scleral thinning after lamellar scleral flap, including one case with confirmed extraocular tumor extension. Methods: The medical records and pathology specimens of three patients with scleral thinning after biopsy and plaque brachytherapy and lamellar scleral flap performed during a transscleral biopsy
\end{abstract}

were reviewed. Results: The first two patients developed scleral thinning and visible pigmentation, but had tumors that were regressing in size on ultrasound. The two patients were followed by serial observation. The third patient exhibited scleral thinning and evidence of tumor growth on ultrasound, raising the suspicion for extraocular tumor extension. Histopathologic examination of the enucleated eye confirmed extrascleral tumor extension and showed necrotic and intact melanoma with associated pigmented macrophages. Conclusions: Patients with scleral flaps created for biopsy of uveal melanoma are at risk for scleral thinning and extrascleral extension of tumor recurrence through the flap.

\section{KARGER}

(c) 2018 S. Karger AG, Basel

E-Mail karger@karger.com

www.karger.com/oop
Hans E. Grossniklaus, MD

1365B Clifton Road, NE

Suite BT428

Atlanta, GA 30322 (USA)

E-Mail ophtheg@emory.edu 


\section{Introduction}

Uveal melanoma is a neoplasm of melanocytes located within the choroid, ciliary body, or iris and is the most common primary intraocular malignant neoplasm in adults [1]. Diagnosis is typically based on findings from the clinical exam and additional imaging tests, such as ultrasound and fluorescein angiography [2]. However, fine-needle aspiration biopsy (FNAB) is now commonly performed to obtain tissue sample for cytogenetic testing and gene expression profiling, which can help assess risk for metastasis $[3,4]$. Treatment of uveal melanoma usually consists of plaque brachytherapy and enucleation [5].

We have recently evaluated three eyes with uveal melanoma which had FNAB using a lamellar scleral flap at the time of plaque brachytherapy placement and subsequently developed scleral thinning over the flap site. Two eyes then developed melanocytic proliferation over the site of the scleral flap and one resulted in extrascleral tumor extension, requiring enucleation.

\section{Case Reports}

\section{Case 1}

A 75-year-old woman presented to our clinic to establish care and follow-up for choroidal melanoma in the left eye. She was diagnosed 4 years prior and received iodine- 125 episcleral plaque brachytherapy at another institution. The total radiation dose information was not available. At that time, a transscleral FNAB was performed, using a 57 blade to create a partial thickness scleral flap and a 27-gauge needle to aspirate tumor material. The scleral flap was closed with 9-0 nylon sutures. Gene expression profiling revealed class 2 melanoma.

At presentation, her best corrected visual acuity was $20 / 40$. Slitlamp examination showed scleral thinning over flap site with choroid showing, vitreous hemorrhage, trace pigment cells in the vitreous, and a brown mass in the anterior periphery. An ultrasound was performed, which showed an elevated choroidal lesion in a dome-shaped configuration, measuring $4.5 \mathrm{~mm}$ in thickness and $10.3 \times 9 \mathrm{~mm}$ in basal diameter. These measurements represented a decrease in size from prior measurements. Repeat slit-lamp examination 7 months later showed increased scleral thinning and ultrasound remeasurement revealed a regressing tumor, $3.8 \times 9.9$ $\times 8.9 \mathrm{~mm}$ in size (Fig. 1, Fig. 2). Because the tumor had decreased in size, this was felt to represent scleral thinning and melting of the scleral flap secondary to radiation therapy. The patient is being followed by serial observation.

Case 2

A 55-year-old male was referred to our clinic for management of choroidal melanoma in the right eye. Four months previously, a choroidal lesion was noted incidentally on a routine MRI of the brain for his multiple sclerosis. Ultrasound revealed a tumor mea- suring $8.8 \times 10.8 \times 11.9 \mathrm{~mm}$ with a mushroom-like configuration. The A-scan component showed low internal reflectivity. About 1 month later, the patient underwent iodine- 125 plaque brachytherapy, receiving a total dose of $85 \mathrm{~Gy}$ to $8.8 \mathrm{~mm}$, and a transscleral FNAB. The surgeon used a 15-degree blade to make a partial thickness scleral flap and a 25 -gauge needle to aspirate a specimen. The flap was closed using 8-0 nylon sutures. The tumor was found to be a class $1 \mathrm{~A}$ subtype on gene expression profiling.

At a follow-up visit 20 months after presentation, VA was $20 / 100$, which pinholed to $20 / 40$, and slit-lamp examination was notable for scleral thinning and a pigmented lesion. The tumor had decreased in size to $3.1 \times 9.0 \times 10.6 \mathrm{~mm}$ by ultrasound examination (Fig. 3, Fig. 4). The pigmentation again was thought not to represent extraocular extension, but rather scleral thinning with an underlying treated melanoma. The patient is being followed by serial observation.

\section{Case 3}

An 80-year-old woman was evaluated in our clinic for ongoing management of a choroidal melanoma in the left eye. Her tumor had been treated 6 years previously with iodine- 125 plaque brachytherapy, receiving a total of $84 \mathrm{~Gy}$ to $13.5 \mathrm{~mm}$. At the time of plaque placement, she underwent a transscleral FNAB using a 15-degree blade to create a partial thickness scleral flap and a 25-gauge needle to aspirate tumor material. Gene expression profiling showed a class $1 \mathrm{~A}$ tumor. Since then, her visual acuity decreased to light perception and she had no pain.

At the time of evaluation, slit-lamp examination was notable for a brown mass protruding at an area of scleral thinning temporally, peripheral neovascularization of the cornea, a shallow anterior chamber filled with cholesterol, vascularization of the iris, and no view of posterior ocular structures (Fig. 5).

Ultrasound showed extrascleral extension of the tumor through the area of scleral thinning (Fig. 6). The tumor measured $14.5 \mathrm{~mm}$ in thickness (including the anterior protrusion) with a base measuring $16.4 \times 15.0 \mathrm{~mm}$. These measurements represented an increase in size from prior measurements.

Given concern for extraocular extension of melanoma, the eye was enucleated. Gross examination of the enucleated eye revealed a heavily pigmented choroidal mass nasally with an overlying scleral defect and the mass extended through the sclera onto the epibulbar surface (Fig. 7). The tumor had broken through Bruch's membrane and assumed a mushroom-shaped configuration. Histopathologic examination showed that approximately $70 \%$ of the tumor was necrotic, with the surrounding portion composed of heavily pigmented cells. The tumor cells were plump, polyhedral cells with centrally placed, small, bland nuclei, and abundant cytoplasm, which was engorged with pink melanin pigment granules. There were scattered melanophages and cholesterol clefts within the tumor. The tumor extended through the sclera, onto the episclera surface, where it formed a nodule, which was covered by a thin layer of fibrovascular tissue. Some tumor cells in the scleral surface had spindle-shaped or oval nuclei with centrally placed nucleoli and marginated chromatin. Examination of the soft tissue adjacent to the optic nerve and the superonasal and inferotemporal vortex veins showed no signs of malignancy. The final diagnosis was malignant melanoma, mixed cell type arising in melanocytoma, and extensive necrosis and extraocular extension. 

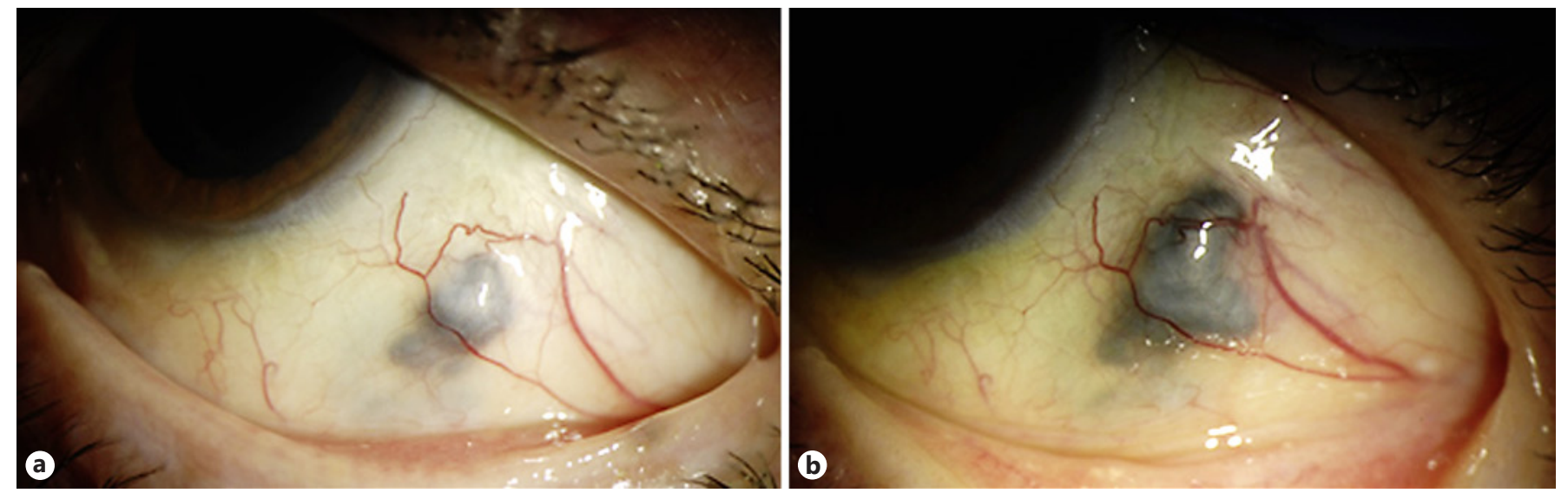

Fig. 1. Case 1. a Appearance of sclera at time of presentation. b One month later, the biopsy site shows a larger, darker protrusion.
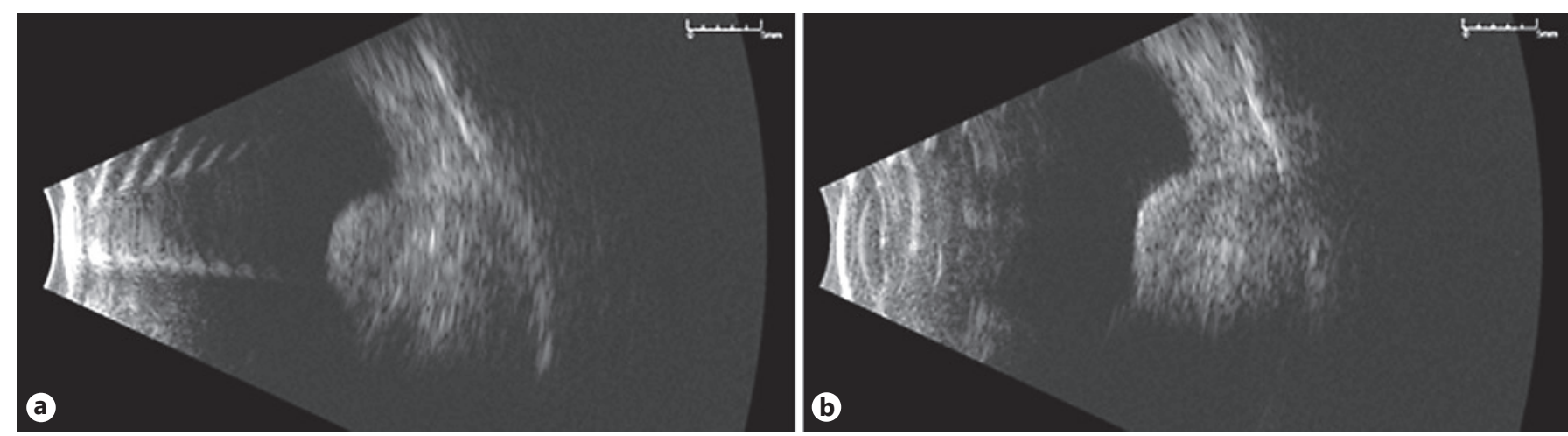

Fig. 2. Case 1. a B-scan ultrasound at the time of presentation shows an anteriorly located mass measuring $4.5 \times 10.3 \times 9.0 \mathrm{~mm}$. b Seven months later, the tumor measures $3.8 \times 9.9 \times 8.9 \mathrm{~mm}$.
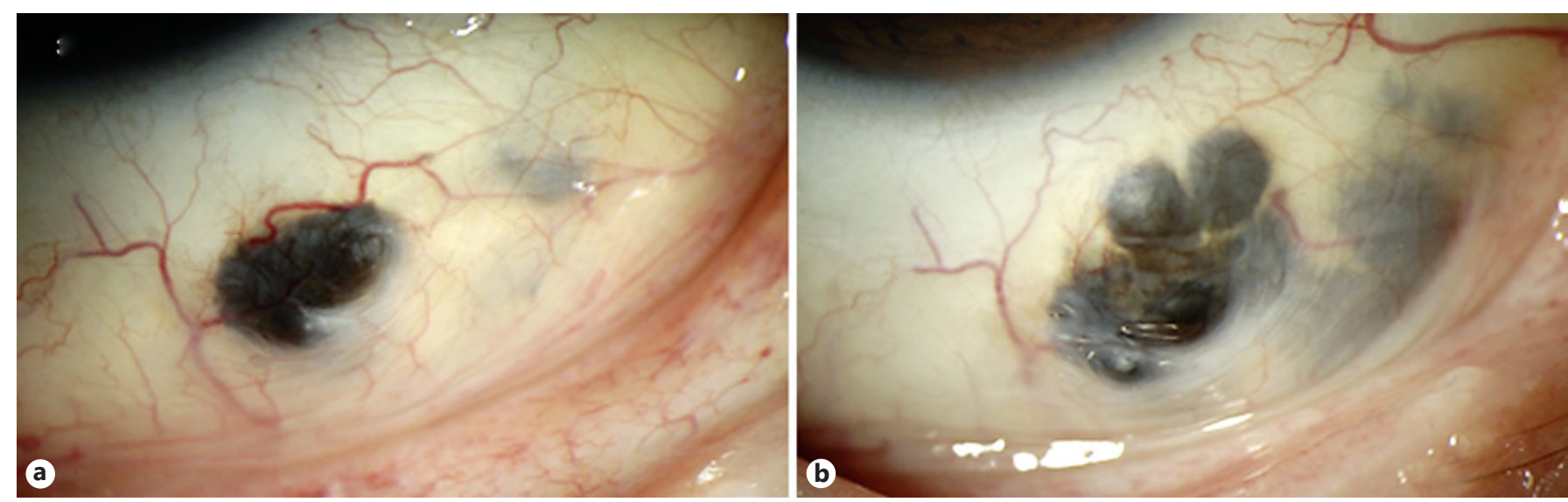

Fig. 3. Case 2. a Fourteen months after initial presentation, scleral thinning and a dark mass are evident. b Six months later, the areas of scleral thinning and dark mass are larger. 

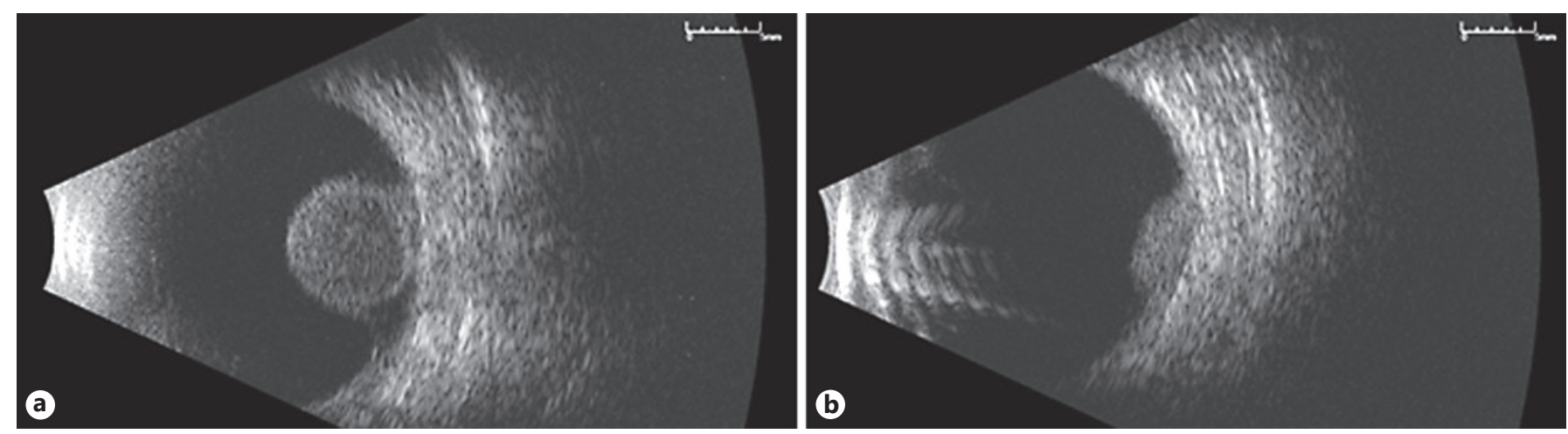

Fig. 4. Case 2. a B-scan ultrasound from the initial presentation shows an anteriorly located tumor measuring $8.8 \mathrm{~mm}$ in thickness with a base that measured $10.8 \times 11.9 \mathrm{~mm}$. b B-scan ultrasound from a follow-up visit 20 months after presentation shows that the tumor measured $5.0 \times 8.9 \times 11.6 \mathrm{~mm}$.
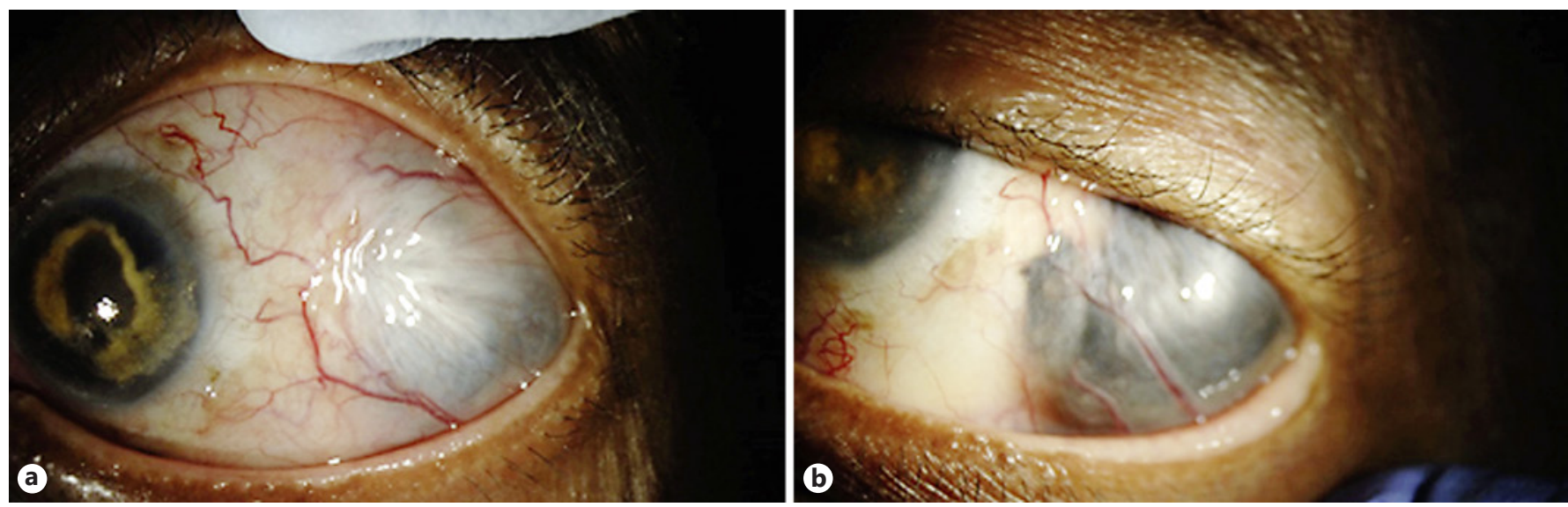

Fig. 5. Case 3. a Appearance of the scleral thinning approximately 3 years prior to $\mathbf{b}$, which shows the mass to have enlarged with more protrusion through the sclera.

\section{Discussion}

All three of our cases developed scleral thinning after transscleral FNAB using a partial thickness scleral flap and radiation treatment of their tumors. Although other etiologies of scleral thinning, such as inflammation from tumor necrosis or surgically induced necrotizing scleritis, are possible, we believe that these cases demonstrate scleral necrosis secondary to radiation therapy. There have been several reports in the literature of scleral necrosis after plaque brachytherapy [6-11]. Overall, however, it is a relatively rare occurrence $(1 \%)$ and the average time to development of scleral necrosis after radiation therapy is 32 months [12]. The cases that we describe here developed of scleral thinning within a comparable timeframe. Our case 1 developed scleral thinning within 31 months after treatment, case 2 within 19 months, and case 3 within 29 months, all consistent with the prior report.

Risk factors of scleral necrosis include: increasing tumor thickness ( $>6 \mathrm{~mm}$ ), ciliary body and peripheral choroidal location (pars plana to ora serrata location of the anterior tumor margin), and higher radiation dose to the sclera ( $>400$ Gy to the outer sclera) [12]. Before plaque placement, case 1 was $6 \mathrm{~mm}$ thick, case 2 was $8.8 \mathrm{~mm}$ thick, and case 3 had a tumor thickness of $13.5 \mathrm{~mm}$. All three of our cases had anteriorly located tumors.

The diagnosis of scleral necrosis is based on clinical findings and must be distinguished from extrascleral tumor extension to avoid unnecessary enucleations or risk 

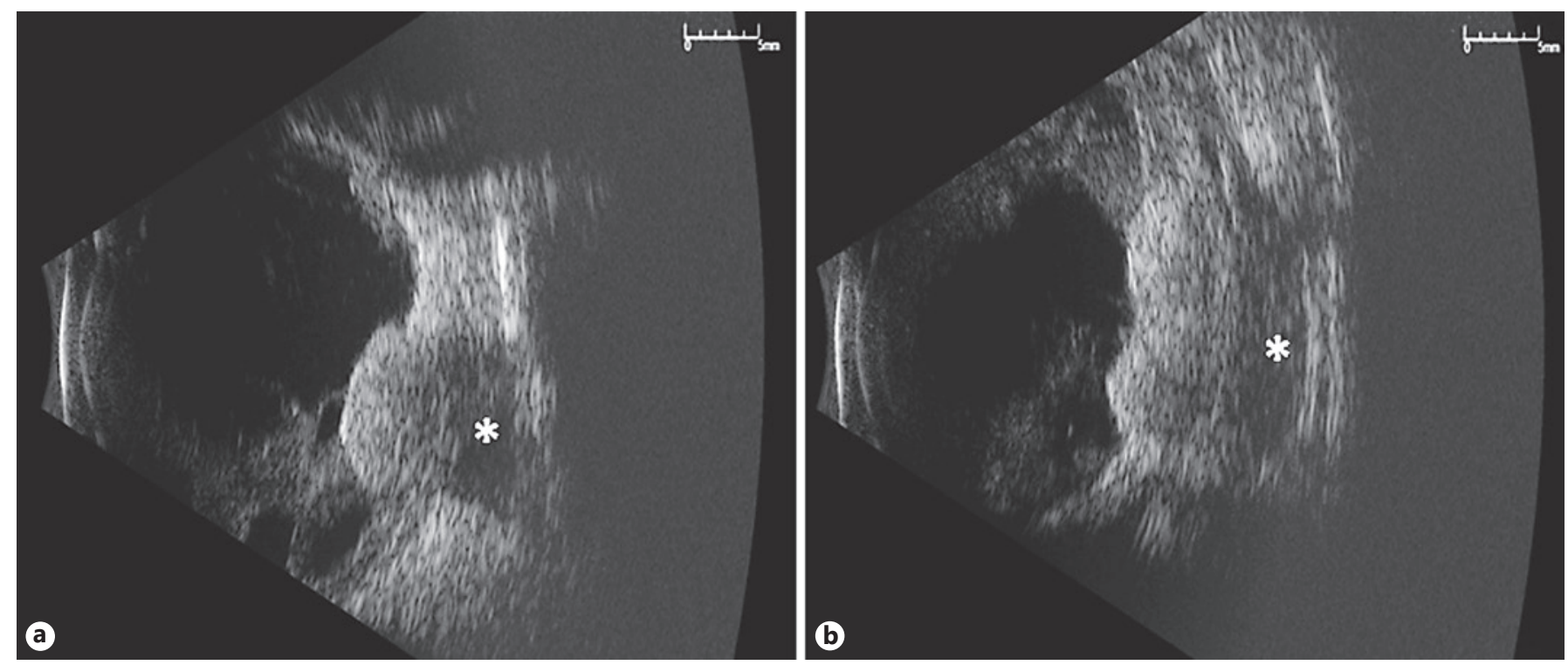

Fig. 6. Case 3. B-scan ultrasound images $(\mathbf{a}, \mathbf{b})$ show that the residual tumor had increased in size from prior imaging, and exhibits extrascleral extension (asterisks).
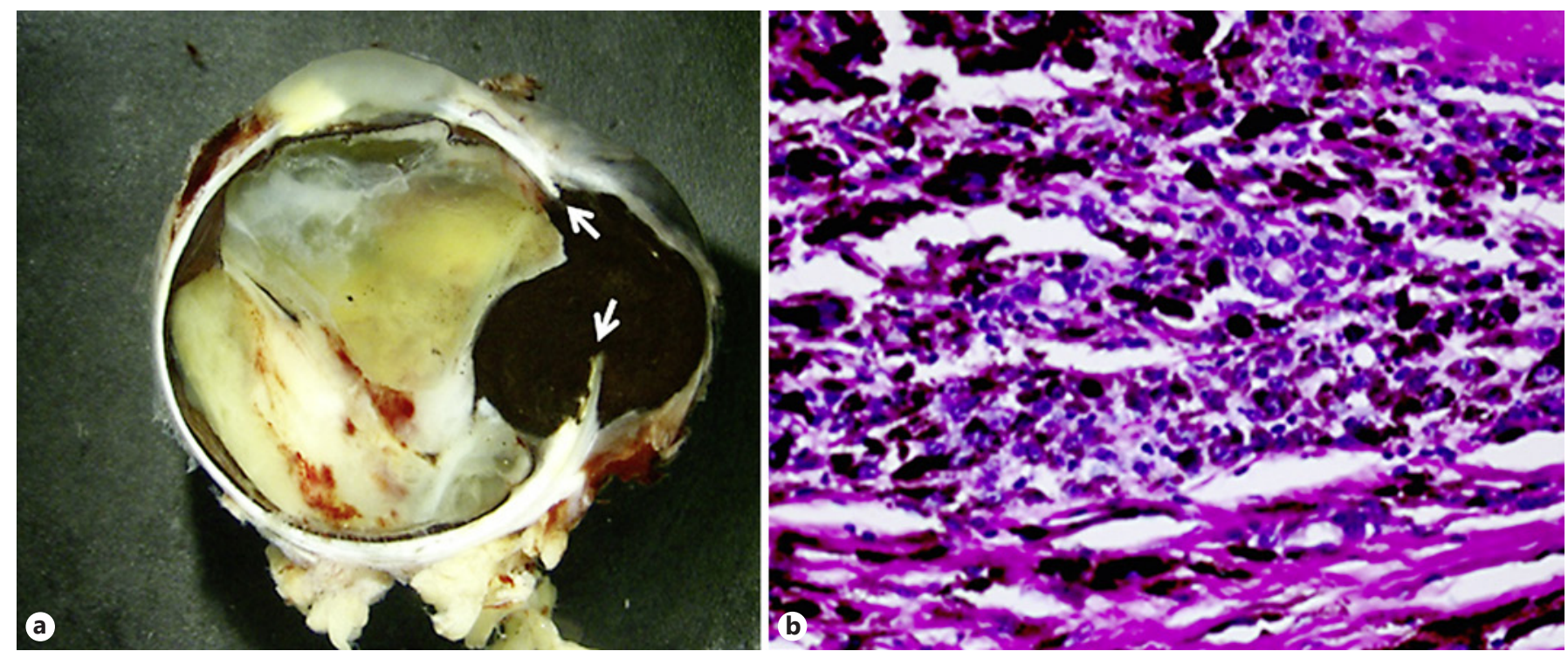

Fig. 7. Case 3. a The enucleated eye contains a pigmented mass protruding through breaks in the sclera (arrows). b There are intact melanoma cells extending through the sclera (hematoxylin and eosin, 100×).

of metastasis. In 1999, Corrêa et al. [9] described a case of early-onset scleral necrosis with tumor extrusion within 1 month of plaque radiotherapy in a 62-year-old with a large ciliochoroidal melanoma, which was treated with enucleation. The distinction between scleral necrosis and tumor extension can be difficult. For example, Hill and
Corrêa [13] describe a case of scleral necrosis in an eye treated with brachytherapy for uveal melanoma that simulated extension of the tumor, though no tumor cells were found outside the sclera once the eye was enucleated. Furthermore, Kaliki et al. [12] found no evidence of scleral involvement of melanoma in 8 eyes that were enu- 
cleated for suspected tumor extensions and signs of scleral necrosis. Ultrasound biomicroscopy (UBM) or anterior segment optical coherence tomography (AS-OCT) can be useful in distinguishing between scleral necrosis and extrascleral tumor extension [12]. UBM and AS-OCT images in our cases were not available.

Scleral necrosis alone can be managed conservatively with observation and lubrication with artificial tears, gels, or ointments [12]. Other management options for scleral necrosis include scleral patch graft, conjunctival graft/ flap, amniotic membrane transplantation, and enucleation, depending on the severity and concern for possible perforation $[12,14]$. We elected to closely observe case 1 and case 2 because they showed only scleral thinning and melanomacrophage proliferation thus far but no increase in tumor size.

Our case 3 showed evidence of scleral thinning and increased subconjunctival pigmentation 3 years prior to enucleation. Later, ultrasound measurements that included the anterior protrusion of the tumor showed an increase in thickness, raising suspicion for likely extrascleral tumor extension, which was confirmed once the eye was enucleated. Recurrence of melanoma after radiation therapy is rare, with a recurrence rate of $3-4.2 \%$ after several years of follow-up $[15,16]$. Local recurrence is associated with a greater risk of distant metastasis, which some hypothesize to be related to the greater malignant potential of the primary uveal melanoma [15].

FNAB of uveal melanomas is generally accepted to be a safe procedure with a low risk of complications $[3,4,17$, 18]. However, there are a few rare case reports in the literature of extrascleral tumor extension after FNAB [19$21]$. None of the FNAB techniques referenced in the case reports definitively describe the use of a partial thickness scleral flap in a transscleral FNAB at the time of plaque brachytherapy placement.

To our knowledge, there has been no discussion in the literature of the role that a lamellar scleral flap may play in the development of future scleral necrosis or extrascleral tumor extension. In one prospective case series, Singh et al. [18] described outcomes in 150 eyes which had FNAB of uveal melanoma, including 71 eyes which had a partial thickness scleral flap at the time of their transscleral biopsy and plaque placement. They reported no tumor recurrence, but did not comment on development of scleral necrosis in the average of 37 months of follow-up [18]. Another recent study on complications of FNAB in uveal melanoma did not appear to include a lamellar scleral flap in their transscleral FNAB technique [17].
The primary techniques used for FNAB include a transvitreal approach for posteriorly located tumors and transscleral methods for anterior lesions. The use of a lamellar scleral flap in the transscleral technique was initially popularized due to concerns for seeding of tumor cells in the subconjunctival space using a straight needle approach. Angi et al. [22] describe a biopsy technique for anteriorly located tumors that consists of an incisional biopsy using Essen forceps through a lamellar scleral flap later sealed by histoacryl glue; this technique improved specimen yield for cytological and genetic analysis compared to the traditional transscleral FNAB technique. This technique includes a near full thickness flap with a wide flap that allows for spreading of the tissue glue. They did not report any tumor recurrence, and did not report on the presence of scleral thinning over their median follow-up time of 9.8 months [22]. We made triangular flaps that measured approximately $3-4 \mathrm{~mm}$ at the base by $3-4 \mathrm{~mm}$ to the apex, $0.5 \mathrm{~mm}$ thick, and closed the flaps with one or two 8-0 nylon sutures at or near the apex; we did not use histoacryl glue. These differences from the Angi technique may have predisposed for scleral thinning.

Our cases illustrate a possible risk of scleral necrosis and possible extrascleral tumor extension in patients who have had plaque brachytherapy and partial thickness scleral flap during FNAB. It is possible that a variation on the lamellar scleral flap biopsy technique, as described by Angi et al. [22], may avoid the complications of scleral necrosis and extrascleral tumor extension. However, further study is needed. Given the potential to confuse the clinical picture, our recommendation is to take precautions when using a lamellar scleral flap during transscleral biopsy.

\section{Acknowledgements}

We would like to thank Drs. Christopher Bergstrom and Prithvi Mruthyunjaya for their participation in the care of these patients and Elizabeth Butker for providing information about the radiation doses of the plaques.

\section{Statement of Ethics}

The study followed the tenets of the Declaration of Helsinki. The Emory University Institutional Review Board granted exempt status to this study. 


\section{Disclosure Statement}

The authors declare no conflicts of interest.

\section{Funding Sources}

Supported in part by NIH P30EY06360 and an unrestricted departmental grant from Research to Prevent Blindness, Inc.

\section{References}

-1 Singh AD, Topham A: Incidence of uveal melanoma in the United States: 1973-1997. Ophthalmology 2003;110:956-961.

2 MaFee MF, Peyman GA, Pease JH, et al: Accuracy of diagnosis of choroidal melanomas in the Collaborative Ocular Melanoma Study. Arch Ophthalmol 1990;108:1268-1273.

-3 McCannel TA: Fine-needle aspiration biopsy in the management of choroidal melanoma. Curr Opin Ophthalmol 2013;24:262-266.

-4 Shields CL, Ganguly A, Bianciotto CG, Turaka K, Tavallali A, Shields JA: Prognosis of uveal melanoma in 500 cases using genetic testing of fine-needle aspiration biopsy specimens. Ophthalmology 2011;118:396-401.

5 Collaborative Ocular Melanoma Study Group: The COMS randomized trial of iodine 125 brachytherapy for choroidal melanoma. Arch Ophthalmol 2006;124:1684-1693.

-6 Chaudhry IA, Liu M, Shamsi FA, Arat YO, Shetlar DJ, Boniuk M: Corneoscleral necrosis after episcleral AU-198 brachytherapy of uveal melanoma. Retina 2009;29:73-79.

-7 Radin PP, Lumbroso-Le Rouic L, Levy-Gabriel C, Dendale R, Sastre X, Desjardins L: Scleral necrosis after radiation therapy for uveal melanomas: report of 23 cases. Graefe's Arch Clin Exp Ophthalmol 2008;246:1731-1736.

8 Gunduz K, Shields C, Shah P, Sivalingam V, Brady L, Woodleigh R: Plaque radiotherapy of uveal melanoma with predominant ciliary body involvement. Arch Ophthalmol 1999; 117:170-177.
\$9 Corrêa ZM, Augsburger JJ, Freire J, Eagle RC Jr: Early-onset scleral necrosis after iodine I 125 plaque radiotherapy for ciliochoroidal melanoma. Arch Ophthalmol 1999;117:259_ 261.

10 Augsburger JJ, Shields JA, Folberg R, Lang W, O'Hara BJ, Claricci JD: Fine needle aspiration biopsy in the diagnosis of intraocular cancer. Cytologic-histologic correlations. Ophthalmology 1985;92:39-49.

11 Shields CL, Naseripour M, Cater J, et al: Plaque radiotherapy for large posterior uveal melanomas ( $>$ or $=8-\mathrm{mm}$ thick) in 354 consecutive patients. Ophthalmology 2002;109: 1838-1849.

12 Kaliki S, Shields CL, Rojanaporn D, et al: Scleral necrosis after plaque radiotherapy of uveal melanoma: a case-control study. Ophthalmology 2013;120:1004-1011.

13 Hill JR, Corrêa ZM: Progressive scleral necrosis following I-125 plaque radiotherapy for ciliochoroidal melanoma with protruding extraocular mass. Ocul Oncol Pathol 2016;2: 136-139.

14 Barman M, Finger PT, Milman T: Scleral patch grafts in the management of uveal and ocular surface tumors. Ophthalmology 2012; 119:2631-2636.

15 Shields CL, Cater J, Shields JA, et al: Combined plaque radiotherapy and transpupillary thermotherapy for choroidal melanoma. Arch Ophthalmol 2002;120:933.
16 Wilson MW, Hungerford JL: Comparison of episcleral plaque and proton beam radiation therapy for the treatment of choroidal melanoma. Ophthalmology 1999;106:15791587.

17 Sellam A, Desjardins L, Barnhill R, et al: Fine needle aspiration biopsy in uveal melanoma: technique, complications, and outcomes. Am J Ophthalmol 2016;162:28-34.e1.

18 Singh AD, Medina CA, Singh N, Aronow ME Biscotti CV, Triozzi PL: Fine-needle aspiration biopsy of uveal melanoma: outcomes and complications. Br J Ophthalmol 2016;100: 456-462.

19 Schefler AC, Gologorsky D, Marr BP, Shields CL, Zeolite I, Abramson DH: Extraocular extension of uveal melanoma after fine-needle aspiration, vitrectomy, and open biopsy. JAMA Ophthalmol 2013;131:1220-1224.

20 Mashayekhi A, Lim RP, Shields CL, Eagle RC Shields JA: Extraocular extension of ciliochoroidal melanoma after transscleral fine-needle aspiration biopsy. Retin Cases Brief Rep 2016;10:289-292.

-21 Caminal JM, Sanz S, Carreras M, Catala I, Arruga J, Roca G: Epibulbar seeding at the site of a transvitreal fine-needle aspiration biopsy. Arch Ophthalmol 2006;124:587-589.

22 Angi M, Kalirai H, Taktak A, et al: Prognostic biopsy of choroidal melanoma: an optimised surgical and laboratory approach. $\mathrm{Br} \mathrm{J}$ Ophthalmol 2017;101:1143-1146. 